\title{
The Fourth Industrial Revolution and Moral Education
}

\author{
Osamu Nakayama \\ Professor, Former President \\ Reitaku Graduate School of Education \\ T277-8686 2-1-1 Hikarigaoka, Kashiwa-City, Chiba Pref., Japan
}

\section{ARTICLE INFO}

Article history

RECEIVED: 09-Sep-19

REVISED: 07-Oct-19

ACCEPTED: 04-Dec-19

PUBLISHED: $16-$ Dec-19

*Corresponding Author:

Email: onakaya@reitaku-u.ac.jp

\begin{abstract}
The fourth Industrial Revolution may have less welcome consequences with the social, political, cultural, and economic upheavals. To cope with their associated problems in Japan in the years ahead, the Japanese Cabinet office has proposed a new concept, "Society 5.0", and has tasked the Ministry of Culture, Sports, Science and Technology to support this policy in the education sector, with a focus on "strengths as human beings" as one of the key policy concerns. The nurturing of such human strengths, however, belongs primarily to the field of moral education rather than that of new technology. Hence there is plenty of room to expand the Japanese concept of Society 5.0.
\end{abstract}

Keywords: Fourth Industrial Revolution, Society 5.0, strengths as human beings, moral education.

Today we face a new era, that of the $4^{\text {th }}$ Industrial Revolution. Its continuing development, driven largely by the convergence of digital, biological, and physical innovations in newly developed fields such as big data, robotics, Al, IoT, biotechnology, and IloT, could well make our lives more convenient and pleasant. But the social, political, cultural, and economic upheavals brought about by the widespread availability of digital technologies could also have less welcome consequences in areas of central concern to us all.

To cope with these developments and their associated problems in Japan in the years ahead, the Japanese Cabinet office has proposed a new concept, "Society 5.0". It defines this as "a human-centered society that balances economic advancement with the resolution of social problems by a system that highly integrates cyberspace and physical space." The concept, it reportedly says, will allow Japan to "become the first country in the world to achieve a human-centered society (Society 5.0) in which anyone can enjoy a high quality of life full of vigor." It claims that it intends to accomplish this by "incorporating advanced technologies in diverse industries and social activities and fostering innovation to create new value." (Cabinet Office 2019). To support this policy in the education sector, it has tasked the Ministry of Culture, Sports,
Science and Technology to prepare our school children and students for the rapid technological change to come, with a focus on "strengths as human beings" as one of the key policy concerns (MEXT 2018).

Here, though, we should remind ourselves that the nurturing of strengths as human beings belongs primarily to the field of moral education rather than that of new technology (Nakayama 2015 pp.39-40. Ryan et al. 2012 p. 9). It can only be achieved through an educational focus on the practice of morals, and this in turn requires human interactions and connectedness that cannot be replicated by inhuman Al or loT. The $3^{\text {rd }}$ Industrial Revolution aimed at the maximization of material products, and we now see that the onrushing $4^{\text {th }}$ Industrial Revolution will pursue the maximization of knowledge and information (Ito 2008 pp.82-84). But while both of these may contribute to the development of our material and knowledge-based civilization, their negative by-products, like the destruction of the natural environment, the dissociation between the material world and the human mind, and psychological and spiritual anomie are sapping, and will continue to sap, basic human strengths. Hence there is plenty of room to expand the Japanese concept of Society 5.0. In particular, never before have we had such an urgent need for moral education to make the best use of IT and AI. 


\section{References}

Cabinet Office (2019). Society 5.0. Retrieved from https:// www8.cao.go.jp/cstp/society5_0/society5_0.pdf

Ito, Shuntaro. 2008 In A Collection of Shuntaro Ito's Works: Comparative Civilizations. Chiba: Reitaku Univ. Press, 7, 59-84. (In Japanese)

Minister's Meeting on Human Resource Development for Society Task Force on Developing Skills to Live Prosperously in the New Age. (2018). "Human Resource Development for Society $5.0 \sim$ Changes to Society, Changes to Learning ".
Retrieved from https://www.mext.go.jp/b_menu/activity/ detail/pdf2018/20180605_001.pdf

Nakayama, Osamu. (2015). Actualizing Moral Education in Japan's Tertiary Sector: Reitaku University's Response to Today's Challenges. Journal of Character Education, 2, 1, 39-50.

Ryan, K., Lerner, B., Bohlin, K., Nakayama, O., Mizuno, S., \& Horiuchi, K. (Eds.). (2012). Happiness and Virtue beyond East and West: Towards a New Global Responsibility. Tokyo, Japan: Charles Tuttle and Co. 